\title{
Resolving Cross-Sensitivity Effect in Fluorescence Quenching for Simultaneously Sensing Oxygen and Ammonia Concentrations by an Optical Dual Gas Sensor
}

\author{
Chih-Yi Liu ${ }^{1}$, Moumita Deb ${ }^{2,3}$, Annada Sankar Sadhu ${ }^{2,3}$, Riya Karmakar 2,3, Ping-Tsung Huang 4 , Yi-Nan Lin ${ }^{2}$, \\ Cheng-Shane Chu ${ }^{5, *}$, Bhola Nath Pal ${ }^{6}$, Shih-Hsin Chang ${ }^{7}$ and Sajal Biring ${ }^{2,3}$ (D
}

1 Institute of Atomic and Molecular Sciences, Academia Sinica, Taipei 10617, Taiwan; chihyiliu@gate.sinica.edu.tw

2 Department of Electronic Engineering, Ming Chi University of Technology, New Taipei City 24301, Taiwan; moumitadeb644@gmail.com (M.D.); annadamcut@gmail.com (A.S.S.); karmakarriya345@gmail.com (R.K.); jnlin@mail.mcut.edu.tw (Y.-N.L.); biring@mail.mcut.edu.tw (S.B.)

3 Organic Electronics Research Center, Ming Chi University of Technology, New Taipei City 24301, Taiwan

4 Department of Chemistry, Fu Jen Catholic University, New Taipei City 24205, Taiwan; 073802@mail.fju.edu.tw

5 Department of Mechanical Engineering, Ming Chi University of Technology, New Taipei City 24301, Taiwan

6 School of Material Science and Technology, Indian Institute of Technology (BHU), Varanasi 221005, India; bnpal.mst@itbhu.ac.in

7 MSSCORPS CO., LTD., Hsinchu 30072, Taiwan; Shih-Hsin.Chang@msscorps.com

Citation: Liu, C.-Y.; Deb, M.; Sadhu, A.S.; Karmakar, R.; Huang, P.-T.; Lin, Y.-N.; Chu, C.-S.; Pal, B.N.; Chang, S.-H.; Biring, S. Resolving Cross-Sensitivity Effect in Fluorescence Quenching for Simultaneously Sensing Oxygen and Ammonia Concentrations by an Optical Dual Gas Sensor. Sensors 2021, 21, 6940. https://doi.org/10.3390/ s21206940

Academic Editor: Peng Miao

Received: 17 September 2021

Accepted: 14 October 2021

Published: 19 October 2021

Publisher's Note: MDPI stays neutra with regard to jurisdictional claims in published maps and institutional affiliations.

Copyright: (c) 2021 by the authors. Licensee MDPI, Basel, Switzerland. This article is an open access article distributed under the terms and conditions of the Creative Commons Attribution (CC BY) license (https:// creativecommons.org/licenses/by/ $4.0 /)$
* Correspondence: cschu@mail.mcut.edu.tw

Abstract: Simultaneous sensing of multiple gases by a single fluorescent-based gas sensor is of utmost importance for practical applications. Such sensing is strongly hindered by cross-sensitivity effects. In this study, we propose a novel analysis method to ameliorate such hindrance. The trial sensor used here was fabricated by coating platinum(II) meso-tetrakis(pentafluorophenyl)porphyrin (PtTFPP) and eosin-Y dye molecules on both sides of a filter paper for sensing $\mathrm{O}_{2}$ and $\mathrm{NH}_{3}$ gases simultaneously. The fluorescent peak intensities of the dyes can be quenched by the analytes and this phenomenon is used to identify the gas concentrations. Ideally, each dye is only sensitive to one gas species. However, the fluorescent peak related to $\mathrm{O}_{2}$ sensing is also quenched by $\mathrm{NH}_{3}$ and vice versa. Such cross-sensitivity strongly hinders gas concentration detection. Therefore, we have studied this cross-sensitivity effect systematically and thus proposed a new analysis method for accurate estimation of gas concentration. Comparing with a traditional method (neglecting cross-sensitivity), this analysis improves $\mathrm{O}_{2}$-detection error from $-11.4 \% \pm 34.3 \%$ to $2.0 \% \pm 10.2 \%$ in a mixed background of $\mathrm{NH}_{3}$ and $\mathrm{N}_{2}$.

Keywords: dual gas sensor; optical gas sensor; cross-sensitivity; fluorescence-based sensor; fluorescence quenching; PtTFPP; eosin Y

\section{Introduction}

Many technologies have been developed for gas sensing, which sees wide applications in various fields such as environmental contaminant detection [1-6]. One of them uses the change in fluorescence intensity of dye molecules in presence of the target analyte gas molecules. Such sensing has attracted great attention because it provides multiple information by detecting optical parameters such as intensity, polarization, decay time, energy transfer, and quenching efficiency [7-11]. In addition, fluorescence-based gas sensing is more popular compared to other spectroscopic methods based on optical measurements of absorption, reflection, interference, Raman scattering, and surface plasmon resonance [9]. Nowadays, numerous fluorescence-based gas sensors have been developed for potential applications [12-16].

With the continual improvement demands from the industry, it is desirable to have a sensor capable of detecting two or more different gases simultaneously. The sensor must 
possess the ability to identify not only species but also the concentration of sensed gases. Such desirability can be fulfilled by a fluorescence-based gas sensor fabricated with several different dyes sensitive to individual analyte gas species [11]. Ideally, each dye produces one or more fluorescence peaks whose intensity can be quenched/enhanced in the presence of a specific gas species. Therefore, the peak intensity variation can be used to determine whether a specific gas is present or not. Furthermore, the variation level can be applied to identify the concentration of the gas species. However, such peak specificity may be incorrect in a real situation, where a fluorescence peak can be quenched/enhanced by two or more different gases simultaneously [17]. Such cross-sensitivity effects strongly hinder the gas detection task, particularly with respect to the accuracy of gas concentration identification. The more gas species are sensed, the more complex the cross-sensitivity created is, leading to severe detection hindrance. Therefore, resolving cross-sensitivity effects is crucial to the development of a fluorescence-based gas sensor with multi-analyte detection ability. Here, we present a systematic study on the cross-sensitivity effect of a fluorescence-based dual gas sensor which detects oxygen and ammonia simultaneously. According to the systematic study, we propose an analysis method to strongly improve the gas concentration detection accuracy in presence of cross-sensitivity effects.

Oxygen is a colorless and odorless gas and is essential to the environment, oceans, agriculture, industry and health. An oxygen concentration range of $19.5-23.5 \%$ in the environment is vital for living life [18]. On the other hand, ammonia also plays a crucial role in agriculture, bioprocessing and food-freshness testing. Its vapor hurts the eyes (>50 ppm) and respiratory system (>500 ppm) of humans [19]. Therefore, many researchers have focused on the development of oxygen and ammonia sensors [20-28]. Recently, we have reported a fluorescence-based dual gas sensor with detection sensitivities of 60 for oxygen and 20 for ammonia [29]. However, this sensor suffers from cross-sensitivity effects and thus fails to properly detect the concentration of the individual gases. Such a drawback could probably be overcome by using the analysis method presented here. Furthermore, it is promising to apply this analysis method for improving the accuracy in the detection of concentration of various fluorescence-based multi-gas sensors.

\section{Experimental}

\subsection{Chemical Materials}

The chemicals used in this study are as follows: Grade 1 filter paper was obtained from Advantec (Tokyo, Japan), platinum(II) meso-tetrakis(pentafluorophenyl)porphyrin (PtTFPP) from Frontier Scientific (Logan, UT, USA). Triton-X100 (analytical grade, 100\%) and tetraethylorthosilane (TEOS, 99.5\%) were from Acros Organics (Geel, Belgium), noctyltriethoxysilane (Octyl-triEOS, 97.5\%) was from Alfa Aesar (Haverhill, MA, USA) and cellulose acetate (CA) powder from Showa Chemicals (Akasaka Minato-Ku, Japan). Other reagents such as $\mathrm{EtOH}(99.5 \%), \mathrm{SiO}_{2}(99.9 \%)$ were purchased from ECHO Chemical Co., Ltd. (Miaoli, Taiwan) and tetrahydrofuran (THF, 99.9\%) was from TEDIA (Fairfield, OH, USA). Eosin-Y (99\%) and acetic acid (99\%) were purchased from Sigma Aldrich (St. Louis, $\mathrm{MO}, \mathrm{USA})$ and $\mathrm{HCl}(32 \%)$ from Shimakyu (Taichung, Taiwan). All the chemicals were used as received without further purification.

\subsection{Trial Sensor Fabrication}

The flowchart in Figure 1a schematically shows the procedures to synthesize oxygenand ammonia- sensing solutions. $0.05 \mathrm{~g}$ of PtTFPP (oxygen-sensing material [30]) was dissolved in $10 \mathrm{~mL}$ of THF to form a dye solution. Thirty $\mu \mathrm{L}$ of this solution was mixed with $30 \mu \mathrm{L}$ of a sol-gel matrix. This mixture was stirred magnetically for $10 \mathrm{~min}$ to create an oxygen-sensing solution. The matrix was prepared as follows: we mixed $4 \mathrm{~mL}$ of TEOS and $0.4 \mathrm{~mL}$ of Octyl-triEOS to form a precursor solution. After that, $\mathrm{EtOH}(1.25 \mathrm{~mL})$ and then $\mathrm{HCl}(0.4 \mathrm{~mL})$ were added to the solution. The mixture was capped and stirred magnetically at room temperature for $1 \mathrm{~h}$, during which Triton-X-100 (0.2 mL) was added to the mixture. Finally, the sol-gel matrix was created. $0.05 \mathrm{~g}$ of eosin- $\mathrm{Y}$ (the ammonia sensing material [31]) 
was dissolved in $10 \mathrm{~mL}$ of THF to form a dye solution. One hundred $\mu \mathrm{L}$ of the dye solution was mixed with $50 \mu \mathrm{L}$ of another matrix mixture and $2 \mathrm{mg}$ of $\mathrm{SiO}_{2}$ nanoparticles. This mixture was stirred magnetically for $10 \mathrm{~min}$ to create an ammonia-sensing solution. The matrix was created by dissolving $0.22 \mathrm{~g}$ of CA powder in $10 \mathrm{~mL}$ acetic acid and stirred magnetically at $40{ }^{\circ} \mathrm{C}$ for $1.5-2 \mathrm{~h}$ to form a transparent solution.

With their large surface areas, porous materials have the benefit of adsorbing numerous detected species and thus are widely applied for various sensing tasks [32-37]. Filter paper is one of the most commonly used porous materials. Here, this material was used to carry the sensing materials for a trial sensor. The fabrication concept of the dual sensor of gases $\left(\mathrm{O}_{2}\right.$ and $\left.\mathrm{NH}_{3}\right)$ is schematically represented in Figure $1 \mathrm{~b}$. We dropped $100 \mu \mathrm{L}$ of ammonia-sensing solution on one side (bottom side) of a piece of filter paper (thickness of $200 \mu \mathrm{m}$ ). The sample was then dried in air at room temperature. After that, a similar process was used again to treat the other side (topside) of the paper with $30 \mu \mathrm{L}$ of the oxygen-sensing solution. Then this sample was dried at room temperature for $24 \mathrm{~h}$ to obtain effective sensing materials. With the sensing materials, the sample functioned as a fluorescent-based dual sensor for simultaneously detecting gases of $\mathrm{O}_{2}$ and $\mathrm{NH}_{3}$.

(a)

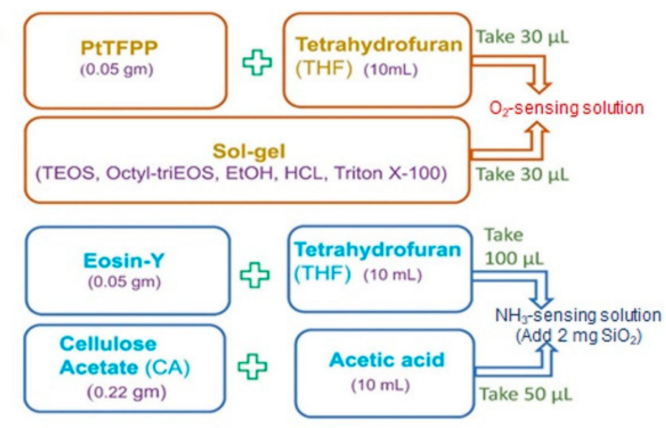

(b)

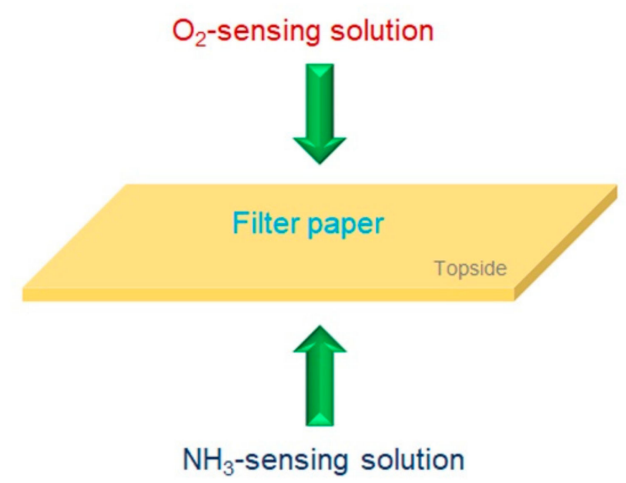

Figure 1. (a) A flow chart showing the synthesis processes of $\mathrm{O}_{2}$ - and $\mathrm{NH}_{3}$-sensing solutions. (b) Schematic diagram representing the fabrication concept of a trial dual sensor.

The filter paper used here was made of many entwined fibers which formed a porous structure, as shown in the typically topside SEM image of Figure 2a. Such a structure contains huge exposed surfaces allowing it to to absorb other materials. After treating with sensing solutions, the sample's fiber surfaces were fully covered by sensing materials, as shown by the typically topside SEM image of Figure 2b. In fact, the sensing solution penetrated the paper in the sensor fabrication process. Therefore, increasing the sensor thickness allows it to absorb more sensing material, leading to stronger fluorescence signals in the subsequent gas detection process. 

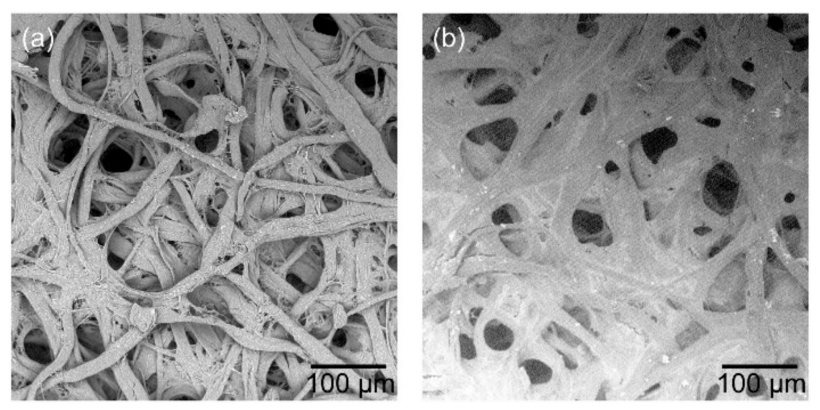

Figure 2. Topside SEM images of a piece of filter (a) before and (b) after treated with sensing solutions. The treatment process is schematically represented in Figure 1.

\subsection{Optical Sensing Instruments}

The instrumental setup for optical sensing is schematically depicted in Figure 3. The sample was excited by a UV light-emitting diode (LED) with a central wavelength of $405 \mathrm{~nm}$ driven by a generator with an arbitrary waveform (TGA1240, Thurlby Thandar Instruments (TTI) Ltd., Huntington, UK) at $10 \mathrm{kHz}$. A fiber optics spectrometer of USB4000 (Ocean Optics Inc., Largo, FL, USA) was employed to measure emission spectra from the trial sensor in the sample chamber.

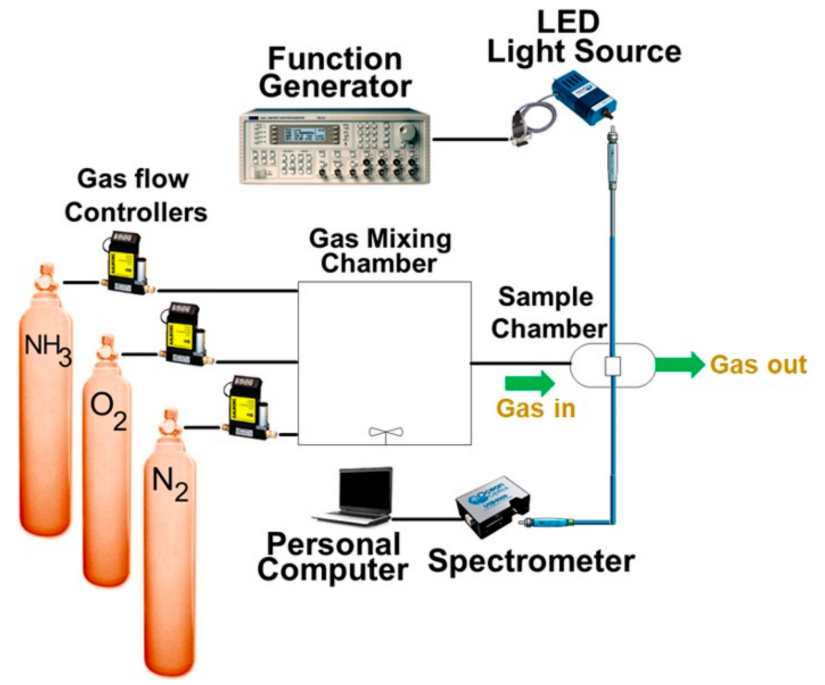

Figure 3. Schematic diagrams of the system setup for optical gas sensing.

$\mathrm{O}_{2}, \mathrm{NH}_{3}$, and $\mathrm{N}_{2}$ flowed into and then out of the sample chamber continuously to control its atmosphere and thus modified emission spectra. Prior to the flow, the gases were ejected into a mixing chamber through mass flow controllers (Model GFC 17, Aalborg Instruments and Controls Inc., Orangeburg, NY, USA) at room temperature. The controllers were able to precisely adjust the flow rate of each gas species and thus set the environmental concentrations of the three gases. In this paper, only the concentrations of $\mathrm{O}_{2}$ and $\mathrm{NH}_{3}$ are indicated since that of the residual $\mathrm{N}_{2}$ can be calculated easily. In fact, $\mathrm{N}_{2}$ was too inert to react with sensing materials and thus barely affected the experimental results. The concentration unit used for $\mathrm{O}_{2}$ is percentage (\%) while that for $\mathrm{NH}_{3}$ is $\mathrm{ppm}$. This is because the two units are commonly used for corresponding sensors from a practical point of view to decide whether the environment is harmful to health.

\section{Results and Discussion}

\subsection{Analysis Theorem}

The sensing materials used in this study are fluorophore compounds which contains a number of active sites to emit fluorescence upon light excitation. Depending on compound characteristics, active sites can be occupied by specific gas molecules. Such occupied sites 
that quench the fluorescence of compounds and related gas molecules are called quenchers. The concentration of quenchers dominates the degree of quenching. Therefore, detection sensitivity, employed to judge the quality of a sensor, can be determined as $I_{0} / \mathrm{I}$, where $\mathrm{I}_{0}$ and I represent the steady-state fluorescence intensities in the absence and presence of quencher. Previous studies indicate that the detection sensitivity follows the Stern-Volmer $(\mathrm{S}-\mathrm{V})$ equation [38]:

$$
\mathrm{I}_{0} / \mathrm{I}=1+\mathrm{K}_{\mathrm{SV}}[\mathrm{Q}]
$$

where $\mathrm{K}_{\mathrm{sv}}$ and [Q] are the Stern-Volmer quenching constant and quencher concentration, respectively. This equation considers the change in fluorescence for an ideal case where all the sensing molecules are sensitive to the quencher, however, in a real situation a number of molecules may be insensitive. Therefore, the equation is rewritten as the modified S-V equation [38-40]:

$$
\mathrm{I}_{0} / \mathrm{I}=\left[\left\{\mathrm{f} /\left(1+\mathrm{K}_{\mathrm{SV}}[\mathrm{Q}]\right)\right\}+(1-\mathrm{f})\right]^{-1}
$$

where $K_{\mathrm{sv}}$ and [Q] are defined as those in Equation (1); $\mathrm{f}$ denotes the fraction of the fluorescence caused by the sensitive molecules in a quencher-free environment. The modified S-V equation properly fitted our results and thus was used to analyze the experimental data.

\subsection{Emission Spectra under Different $\mathrm{O}_{2}$ and $\mathrm{NH}_{3}$ Concentrations}

Figure 4 a shows the emission spectra from the trial dual sensor obtained by systematically varying the $\mathrm{O}_{2}$ concentration in a $\mathrm{NH}_{3}$-free environment. The fluorescence peak of PtTFPP dye at $650 \mathrm{~nm}$ (called " $\mathrm{O}_{2}$-sensitive peak" hereafter) is used to detect $\mathrm{O}_{2}$ since its intensity clearly reduces upon increasing the gas concentration. Similarly, the fluorescence peak of eosin- $\mathrm{Y}$ at $580 \mathrm{~nm}$ is sensitive to $\mathrm{NH}_{3}$ in an $\mathrm{O}_{2}$-free environment (called " $\mathrm{NH}_{3}$ sensitive peak" hereafter), as revealed in Figure $4 \mathrm{~b}$. The spectrum (the inset in Figure $4 \mathrm{~b}$ ) points out that the peak intensity was reduced gradually with the increase in $\mathrm{NH}_{3}$ concentration. However, the change in $\mathrm{NH}_{3}$ concentration alters not only this peak, but also the $\mathrm{O}_{2}$-sensitive one as shown in Figure $4 \mathrm{~b}$. In fact, the $\mathrm{NH}_{3}$-sensitive peak is also quenched by $\mathrm{O}_{2}$ as shown in the inset of Figure $4 \mathrm{a}$. The combined observation from Figure $4 \mathrm{a}, \mathrm{b}$ and their insets imply that both the $\mathrm{O}_{2}$ and $\mathrm{NH}_{3}$ peaks suffer from cross-sensitivity when the environmental atmosphere simultaneously contains $\mathrm{O}_{2}$ and $\mathrm{NH}_{3}$ gases. For example, Figure $4 \mathrm{c}$ and its inset show the emission spectra of the dual sensor by systematically varying $\mathrm{O}_{2}$ concentration in an environment containing $200 \mathrm{ppm}$ of $\mathrm{NH}_{3}$. Compared with the ammonia-free case (Figure $4 \mathrm{a}$ ), both the $\mathrm{O}_{2}$ and $\mathrm{NH}_{3}$-sensitive peaks show less intensities for a given oxygen concentration indicating that the cross-sensitivity effect needs to be addressed in gas sensing.

Cross-sensitivity effects strongly hinder the quantitative detection of gas concentrations since more than one gas species may contribute to the intensity variation of a sensing peak. Such quantitative detection is indispensable for a gas sensor for practical applications and thus developing an analysis method for the quantification is highly demanded. Such analysis is based on highly accurate data, however, the $\mathrm{O}_{2}$ - and $\mathrm{NH}_{3}$-sensitive peaks are too close to be well-separated (Figure $4 \mathrm{a}, \mathrm{c}$ ), thus hindering the collection of accurate data. The situation gets even worse since additional peaks, e.g., the one around $710 \mathrm{~nm}$ interfere with the intensity measurement. Therefore, extracting accurate peak intensities is necessary for further data analysis and will be presented in the followed subsection. A systematic study on PtTFPP peaks of 650 and $710 \mathrm{~nm}$ varying with different oxygen and ammonia concentrations is presented in Appendix A. 


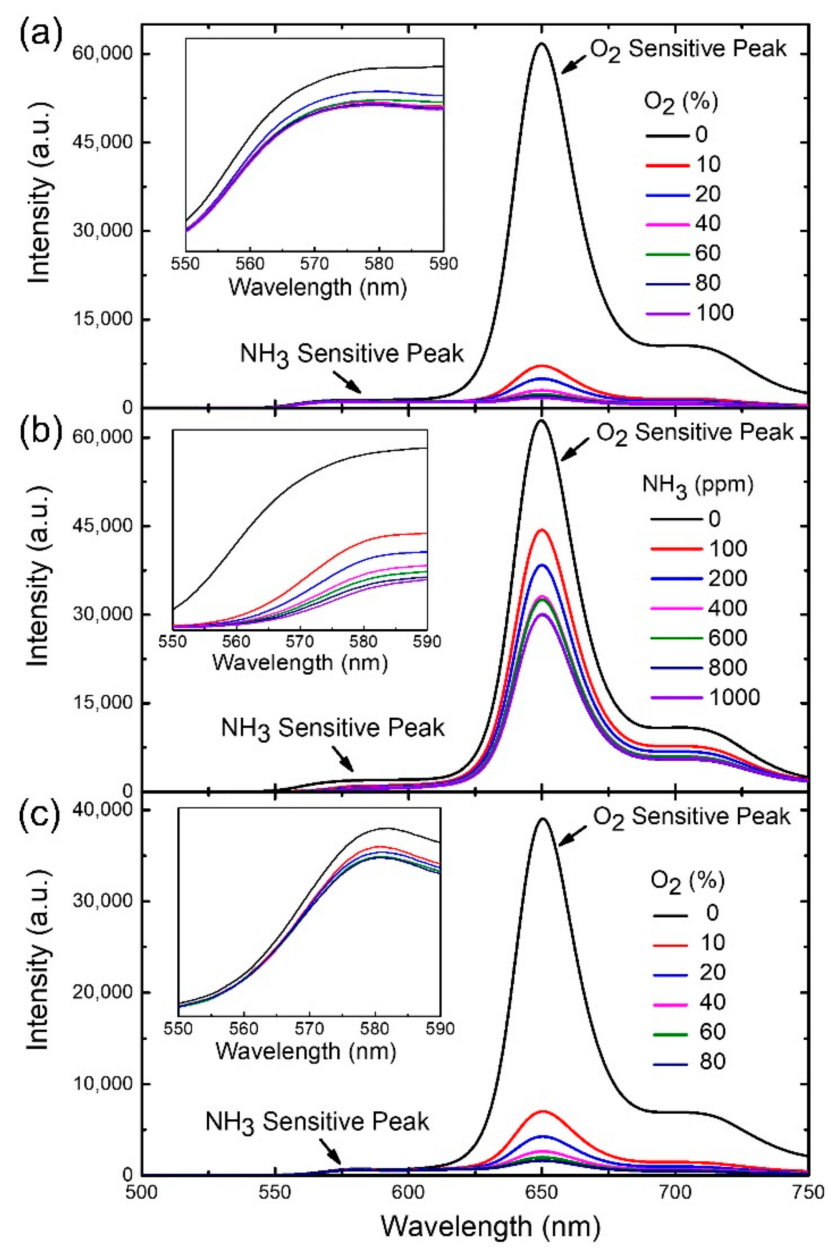

Figure 4. Systematic study of the emission spectra of a trial dual sensor under (a) 0 ppm of $\mathrm{NH}_{3}$, (b) $0 \%$ of $\mathrm{O}_{2}$ and (c) $200 \mathrm{ppm}$ of $\mathrm{NH}_{3}$. The insets show the enlarged areas for $\mathrm{NH}_{3}$-sensitive peaks in the corresponding spectra. The intensity units for the insets are arbitrary units.

\subsection{Spectra Fitting}

We employed Gaussian fitting to analyze the measured emission spectra for extracting more accurate positions and intensities of fluorescent peaks. This analysis is applicable to spectra corresponding to any concentration of $\mathrm{O}_{2}$ and $\mathrm{NH}_{3}$. For example, Figure 5 shows an emission spectrum (black curve) under conditions of $40 \%$ of $\mathrm{O}_{2}$ and $400 \mathrm{ppm}$ of $\mathrm{NH}_{3}$. A Gaussian fitting indicates that the spectrum can be separated into four different parts which are displayed by the red, light green, blue, and light blue curves in Figure 5, respectively. Addition of the four fitted curves together creates the purple one which is quite similar to the original spectrum. The four curves have four peaks marked as "Peaks 1-4" in Figure 5. Peaks 3 and 4 originate in the material for oxygen sensing while the others come from that used for ammonia detection. Each gas species only needs one peak to monitor its concentration. In other words, only two peaks are required for the current gas mixture sensing. We selected Peak 1 (called "fitted $\mathrm{NH}_{3}$-sensitive peak" hereafter) for $\mathrm{NH}_{3}$ sensing and Peak 3 (called "fitted $\mathrm{O}_{2}$-sensitive peak" hereafter) for $\mathrm{O}_{2}$ detection because of their higher peak intensities. The variation in the intensity of the peaks reflects the change in gas concentrations and will be discussed later. 


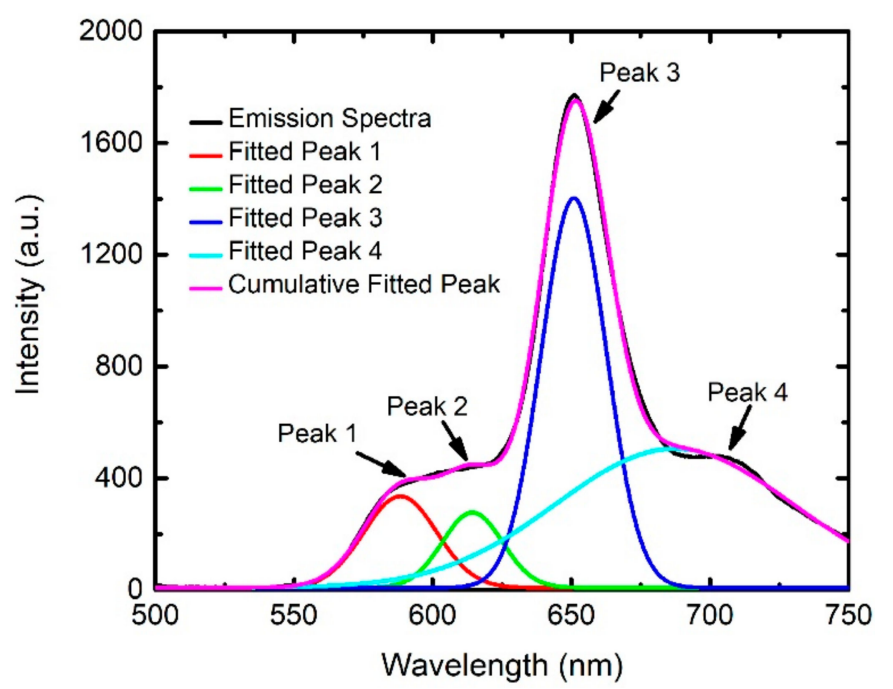

Figure 5. A typical example showing the Gaussian fitting of the emission spectra under conditions of $40 \% \mathrm{O}_{2}$ and $400 \mathrm{ppm} \mathrm{NH}_{3}$.

\subsection{Spectral Analysis for Single Gas Species}

Prior to studying the cross-sensitivity effect, we need to understand how sensing peaks change with single gas species. Such study is relatively simple and can provide crucial information for the exploration of complicated cross-sensitivity effects. Figure $4 a\left(\mathrm{O}_{2}\right.$ only) and $4 \mathrm{~b}\left(\mathrm{NH}_{3}\right.$ only) shows the emission spectra for such a study. Gaussian fitting was used for the spectra in Figure $4 \mathrm{~b}$ to obtain fitted $\mathrm{NH}_{3}$-sensitive peaks for different ammonia concentrations while those in Figure 4a were used to acquire fitted $\mathrm{O}_{2}$-sensitive peaks for distinct oxygen concentrations. In addition, the fitted peaks were employed to calculate the detection sensitivity of the corresponding gas species (refer to Section 3.1). Figure 6a shows the plot of the sensitivity as a function of the ammonia concentration in an oxygen-free $\left(\mathrm{NH}_{3}\right.$ only) environment. The increasing trend of the plot quantitatively indicates the ability of fluorescence quenching caused by ammonia. The maximum detection sensitivity is 4.8 for a $\mathrm{NH}_{3}$ concentration of $1000 \mathrm{ppm}$. A similar increasing trend was also observed in the $\mathrm{O}_{2}$-only case, as shown in the plot of the sensitivity as a function of the oxygen concentration in an ammonia-free environment (Figure 6b). The maximum detection sensitivity is 47 for an $\mathrm{O}_{2}$ concentration of $100 \%$.

Equation (2) was used to fit the measured sensitivity-concentration data, as shown in the red curves in Figure $6 \mathrm{a}\left(\mathrm{NH}_{3}\right.$ only) and $6 \mathrm{~b}\left(\mathrm{O}_{2}\right.$ only). The fittings are correct since their coefficients of determination are both larger than 0.99 . The fitting indicates parameters of $\mathrm{f}=0.84$ and $\mathrm{K}_{\mathrm{SV}}=0.14 \mathrm{ppm}^{-1}$ for the ammonia-only case and $\mathrm{f}=0.99$ and $\mathrm{K}_{\mathrm{SV}}=0.71 \%^{-1}$ for the oxygen-only one. For the ammonia-only case, the $\mathrm{f}$ of 0.84 deviates somewhat from 1 , implying that $\sim 16 \%$ of ammonia-sensing dye is insensitive to $\mathrm{NH}_{3}$. For the other case, the $\mathrm{f}$ of 0.99 quite close to $1 \mathrm{implies}$ that most of oxygen-sensing dye molecules are sensitive to $\mathrm{O}_{2}$. The fitted $\mathrm{f}$ and $\mathrm{K}_{\mathrm{SV}}$ used to estimate the gas concentration of the sensed atmosphere will be discussed later. 

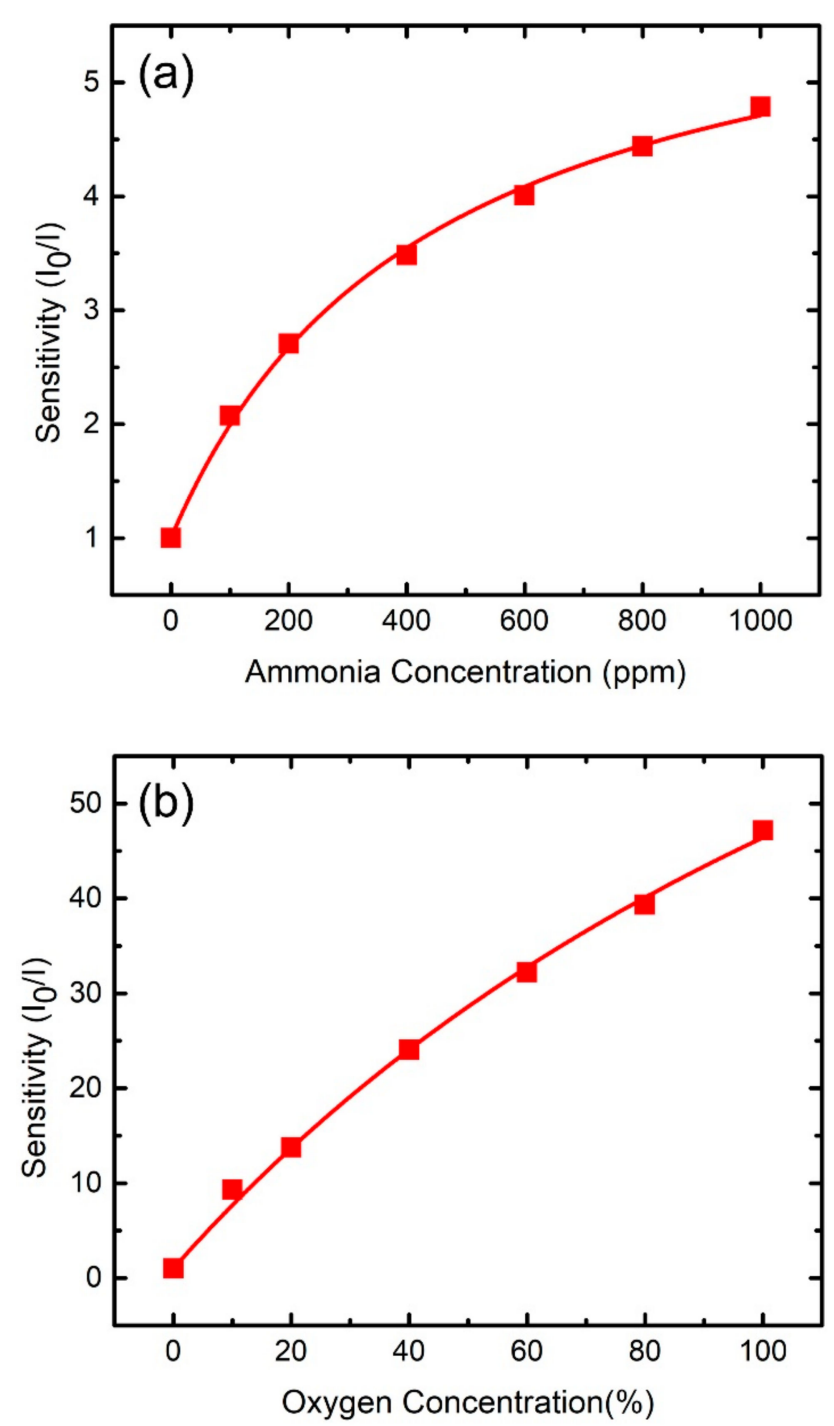

Figure 6. Sensitivity $\left(\mathrm{I}_{0} / \mathrm{I}\right)$ of (a) fitted $\mathrm{NH}_{3}$-sensitive peak as a function of ammonia concentration under an oxygen-free environment and (b) fitted $\mathrm{O}_{2}$-sensitive peak as a function of oxygen concentration under an ammonia-free environment. Equation (2) is used to fit the data points as shown by the red curves.

\subsection{Systematic Study of Cross-Sensitivity Effect}

Mixtures of two gases, i.e., oxygen and ammonia, were used in this study (the influence of nitrogen is considered negligible). To explore the cross-sensitivity effect, we measured emission spectra from the trial sensor under systematically varied concentrations of $\mathrm{O}_{2}$ and $\mathrm{NH}_{3}$. The spectra were then analyzed by a method similar to that described in Section 3.4 to acquire the corresponding sensitivity, $\mathrm{f}$, and $\mathrm{K}_{\mathrm{SV}}$ values. Figure $7 \mathrm{a}$ shows the plot of sensitivity of the fitted $\mathrm{NH}_{3}$-sensitive peak as a function of ammonia concentration under different oxygen environments. The sensitivity varies with different oxygen environments for a fixed ammonia concentration. The relation between sensitivities and ammonia concentrations fits Equation (2), no matter under which oxygen environment, as shown by the colored curves in Figure $7 \mathrm{a}$. Figure $7 \mathrm{~b}$ shows values of $\mathrm{f}$ and $\mathrm{K}_{\mathrm{SV}}$ as functions of the $\mathrm{O}_{2}$ concentration based on the fitting curves in Figure 7a. The parameter $\mathrm{f}$ has an average value of 0.79 and standard deviation of 0.07 , which implies $f$ fluctuates within $\sim \pm 10 \%$. In addition, no clear correlation between $\mathrm{f}$ and oxygen concentration is observed in Figure $7 \mathrm{~b}$ (red squares). Therefore, we infer that environmental oxygen gas does not significantly change the amount of sensitive dye molecules for $\mathrm{NH}_{3}$ sensing. Unlike $\mathrm{f}, \mathrm{K}_{\mathrm{SV}}$ monotonically decreases with increasing oxygen concentration, as shown by the blue dots 
in Figure $7 \mathrm{~b}$. Thus, the coupling between $\mathrm{NH}_{3}$ molecules and ammonia-sensing dyes is reduced by environmental oxygen gas. The higher oxygen concentration leads to a lower coupling. The maximum $\mathrm{K}_{\mathrm{SV}}\left(0.014 \mathrm{ppm}^{-1}\right.$ at $\left.0 \% \mathrm{O}_{2}\right)$ is seven times the minimum one $\left(0.002 \mathrm{ppm}^{-1}\right.$ at $\left.80 \% \mathrm{O}_{2}\right)$, as shown by the blue dots in Figure $7 \mathrm{~b}$. Such a large variation of $\mathrm{K}_{\mathrm{SV}}$ implies that the coupling can be strongly modified by background oxygen. As a result, we speculate that oxygen-induced coupling reduction is the main reason causing the sensitivity changes observed in different oxygen environments for a fixed ammonia concentration, as shown in Figure 7a.
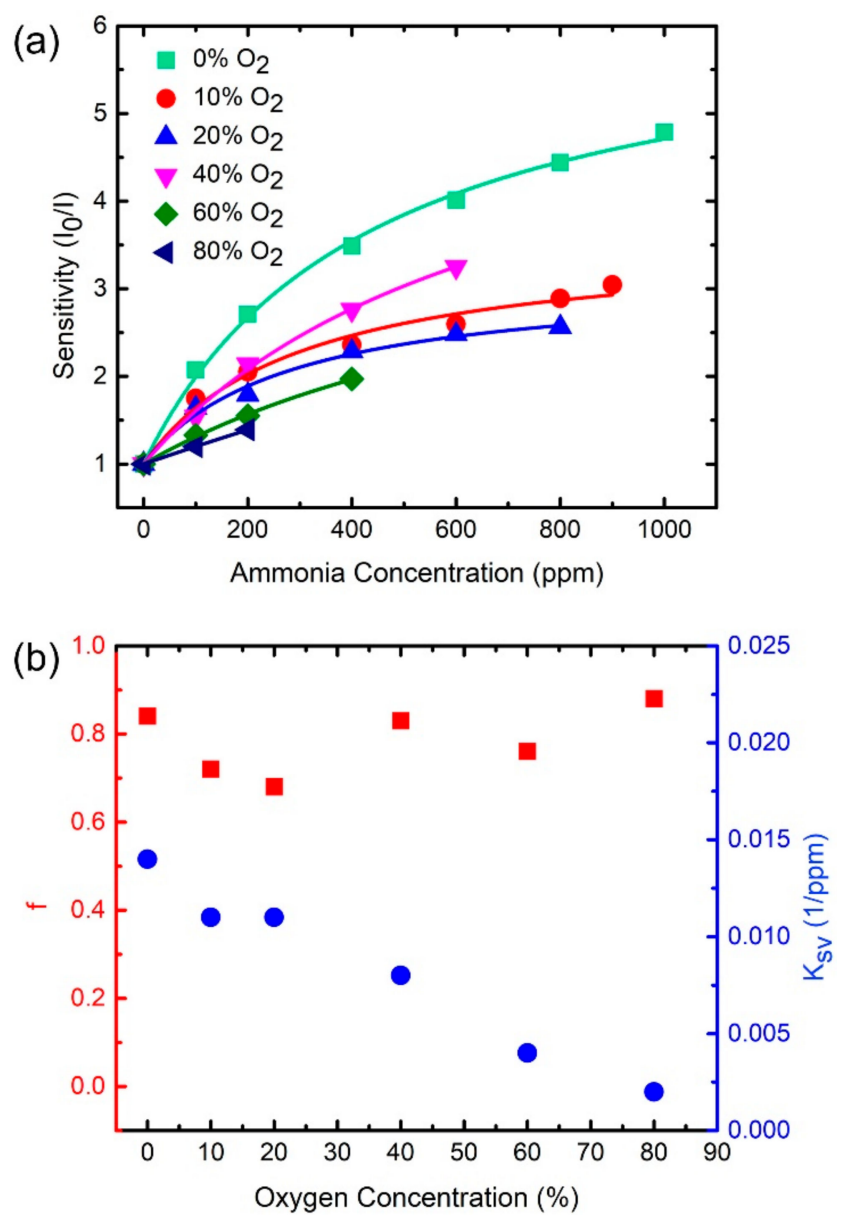

Figure 7. (a) Sensitivity $\left(\mathrm{I}_{0} / \mathrm{I}\right)$ of fitted $\mathrm{NH}_{3}$ sensitive peak as a function of ammonia concentration under systematically varying environmental oxygen concentration. Equation (2) is used to fit the data points as shown by the colored curves. (b) $\mathrm{f}$ (red squares) and $\mathrm{K}_{\mathrm{SV}}$ (blue dots) as a function of oxygen concentration based on the fitted colored curves in (a). The $f$ and $\mathrm{K}_{\mathrm{SV}}$ are parameters in Equation (2).

We also systematically studied the sensitivity of the fitted $\mathrm{O}_{2}$-sensitive peak as a function of the oxygen concentration under different ammonia environments, as shown in Figure 8a. This figure indicates that the relation between sensitivities and oxygen concentrations fits Equation (2) no matter under which ammonia environment is used, as shown by the colored curves in Figure 8a. We obtained values of $\mathrm{f}$ (red squares in Figure $8 \mathbf{b}$ ) and $\mathrm{K}_{\mathrm{SV}}$ (blue dots in Figure $8 \mathrm{~b}$ ) as functions of $\mathrm{NH}_{3}$ concentrations based on the fitting curves in Figure 8a. The parameter $\mathrm{f}$ has an average value of 0.98 and standard deviation of 0.005 , which imply that $\mathrm{f}$ fluctuates within a small range of $\sim \pm 0.5 \%$. Such a small standard deviation implies that $\mathrm{f}$ barely changes for any $\mathrm{NH}_{3}$ environment. In addition, the $\mathrm{f}$ value is quite close to one, implying that most of the oxygen-sensing molecules are sensitive to the $\mathrm{O}_{2}$ concentration. In other words, an ammonia environment barely changes the amount of oxygen-sensitive dye molecules. Roughly speaking, this 
inference is similar to that observed for the case of the fitted $\mathrm{NH}_{3}$-sensitive peak presented in the last paragraph. Unlike $\mathrm{f}$, a significant change in $\mathrm{K}_{\mathrm{SV}}$ values with different ammonia concentrations implies that the coupling between oxygen-sensing molecules and $\mathrm{O}_{2}$ is modified by the $\mathrm{NH}_{3}$ environment. The maximum $\mathrm{K}_{\mathrm{SV}}$ of $0.71 \%{ }^{-1}$ is observed at a $\mathrm{NH}_{3}$ free environment. The $\mathrm{K}_{\mathrm{SV}}$ substantially reduces to $0.3 \%^{-1}$ for a $\mathrm{NH}_{3}$ concentration of $100 \mathrm{ppm}$ and maintains approximately the same value of $0.5 \%{ }^{-1}$ for higher $\mathrm{NH}_{3}$ cases, as shown by the blue dots in Figure $8 \mathrm{~b}$. Such a trend is qualitatively different with that of the fitted $\mathrm{NH}_{3}$-sensitive peak presented in the last paragraph. Following a discussion similar to that for Figure 7a presented in the last paragraph, we again speculate the ammoniainduced coupling variation is responsible for the sensitivity changes observed in different ammonia environments for a fixed oxygen concentration, as shown in Figure 8a. The study of the cross-sensitivity presented in this subsection provides crucial information for sensing concentrations of oxygen and ammonia and will be discussed in the following subsection.
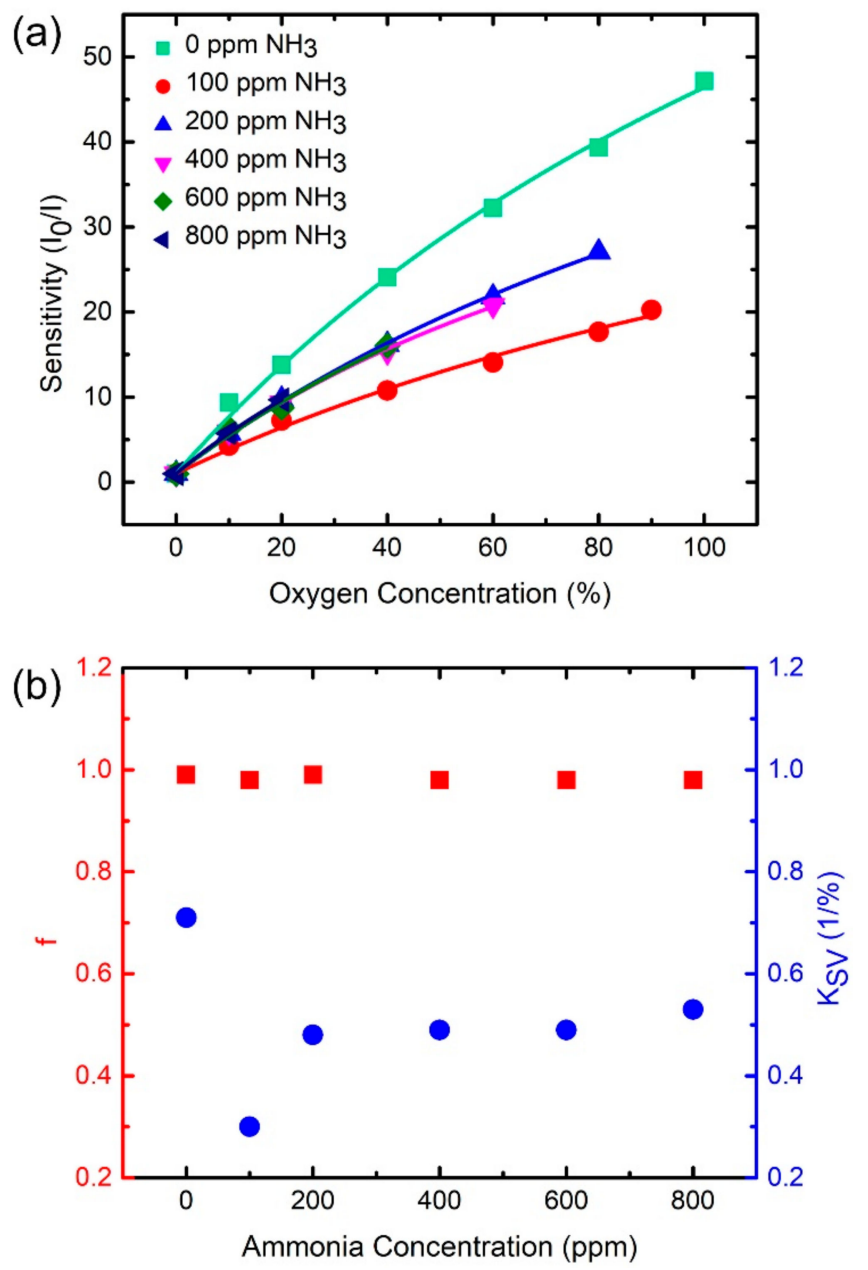

Figure 8. (a) Sensitivity $\left(\mathrm{I}_{0} / \mathrm{I}\right)$ of a fitted $\mathrm{O}_{2}$-sensitive peak as a function of oxygen concentration under systematically varying environmental ammonia concentrations. Equation (2) is used to fit the data points, as shown by the colored curves. (b) $\mathrm{f}$ (red squares) and $\mathrm{K}_{\mathrm{SV}}$ (blue dots) as a function of ammonia concentration based on the fitted colored curves in (a). The $f$ and $\mathrm{K}_{\mathrm{SV}}$ are parameters in Equation (2).

\subsection{Estimation of Gas Concentration}

The main goal of our study was to develop a method to improve gas concentration estimations of sensing methods with cross-sensitivity effects. The process starts by measuring an emission spectrum from a sensed atmosphere to obtain fitted $\mathrm{O}_{2}$ - and $\mathrm{NH}_{3}$-sensitive peaks (refer to Section 3.3). The fitted peaks are then used to calculate the sensitivities. We 
tried to neglect any cross-sensitivity effect and used the values of $\mathrm{f}$ and $\mathrm{K}_{\mathrm{SV}}$ presented in Section 3.4 to analyze the sensitivities because of the relatively simple process. The $f$ and Ksv values together with the calculated sensitivities were substituted into Equation (2) to estimate the ammonia and oxygen concentrations. This analysis method is called hereafter the direct method. We arbitrarily selected seven cases of different oxygen and ammonia concentrations for testing the accuracy of estimated gas concentrations by the direct method, which resulted in the errors show in Table 1. The error is calculated as (real concentration-estimated concentration)/(real concentration) where the real concentration is controlled by the experimental setting. This table indicates an average error of $-1.2 \%$ and standard deviation of $4.2 \%$ for $\mathrm{NH}_{3}$ sensing. In general, a scientific measurement displaying an error within $\sim 5 \%$ is considered acceptable. However, the $\mathrm{O}_{2}$ sensing analysis leads to an average error of $-11.4 \%$ and standard deviation of $34.3 \%$, i.e., the accuracy is too poor to be acceptable. Therefore, the analysis method to estimate $\mathrm{O}_{2}$ concentration needs to consider cross-sensitivity effect for better accuracy.

Table 1. Error of quantitative analysis for gas concentration.

\begin{tabular}{cccccccc}
\hline Case Number & $\mathbf{1}$ & $\mathbf{2}$ & $\mathbf{3}$ & $\mathbf{4}$ & $\mathbf{5}$ & $\mathbf{6}$ & $\mathbf{7}$ \\
\hline Real NH $\mathrm{NH}_{3}$ concentration $(\mathrm{ppm})$ & 50 & 500 & 150 & 150 & 700 & 50 & 500 \\
Real $\mathrm{O}_{2}$ concentration (\%) & 5 & 5 & 10 & 20 & 20 & 30 & 50 \\
\hline $\mathrm{NH}_{3}$-concentration error by the direct method $(\%)$ & 0.1 & 5.1 & -4.5 & -5.8 & 3.3 & -0.2 & -6.3 \\
$\mathrm{O}_{2}$-concentration error by the direct method $(\%)$ & 23.3 & -42.4 & 20.9 & 10.2 & -65.0 & 15.7 & -42.3 \\
$\mathrm{O}_{2}$-concentration error by the modified method $(\%)$ & 13.6 & 6.1 & 15.9 & -0.2 & -11.9 & 1.9 & -11.7 \\
\hline
\end{tabular}

As mentioned above, the direct method is able to provide $\mathrm{NH}_{3}$ concentrations with acceptable errors, however, the determination of oxygen concentrations needs to take into account of cross-sensitivity effect, which causes $\mathrm{f}$ and $\mathrm{K}_{\mathrm{sv}}$ for $\mathrm{O}_{2}$ sensing to be different from that in a $\mathrm{NH}_{3}$-free environment (Figure $8 \mathrm{~b}$ ). Thus, we used the direct method to estimate ammonia concentrations in any environment under study. Then this concentration viewed as the $\mathrm{NH}_{3}$ background was employed to determine $\mathrm{f}$ and $\mathrm{K}_{\mathrm{sv}}$ for $\mathrm{O}_{2}$ sensing by an interpolation method using the data in Figure $8 \mathrm{~b}$. The determined $\mathrm{f}$ and $\mathrm{K}_{\mathrm{sv}}$ together with the calculated sensitivity corresponding to the fitted $\mathrm{O}_{2}$-sensitive peak were then substituted into Equation (2) to estimate the accurate oxygen concentration. This analysis method, called modified method hereafter, was used to estimate oxygen concentrations for the test cases (environments with different mixture of $\mathrm{O}_{2}$ and $\mathrm{NH}_{3}$ gases) in Table 1 . The absolute value of the error for the oxygen concentration estimation by this method is dramatically smaller than that obtained by the direct method, as presented in Table 1. Comparing with the direct method, this analysis improves the average error from $-11.4 \%$ to $2.0 \%$ and the standard deviation from $34.3 \%$ to $10.2 \%$. Figure 9 shows the plot of estimated oxygen-concentration errors as a function of case number for the direct (blue square) and modified (red dots) methods. This figure clearly indicates that the error for each case obtained by the modified method in comparison with that obtained by the direct one is notably closer to 0 . Such a prominent improvement indicates that the modified method is indeed useful and probably can be applied for other fluorescence-based analyte sensing tasks. It is worthwhile to note that all the gaseous mixtures for the testing cases in Table 1 are different from those for the data points in Figures 7 and 8 to guarantee the accuracy of modified method in a completely unknown atmosphere.

Although the modified method reduces the detection error, it may be still insufficient for practical applications. Developing proper dyes for sensors with low cross-sensitivity is needed. The modified method can help such sensors reduce the detection error to achieve a qualified accuracy. Using a single sensor instead of many sensors for multi-gas detection has many advantages such as cost reduction and the possibility of device miniaturization, however, cross-sensitivity effects strongly hinder the development of fluorescence-based multi-gas sensors and thus more work contributions on devices for single species detec- 
tion is needed. The current analysis sheds some light to help researchers overcome the hindrance. In addition, this analysis is only applied for two-gas detection. Detecting gas mixtures containing more than two species may be required in many situations. The cross-sensitivity effects for such a detection may be more complicated. A systematic study similar to that presented here could help to resolve the complexity and thus provide crucial information for the development of fluorescence-based multi-gas sensors.

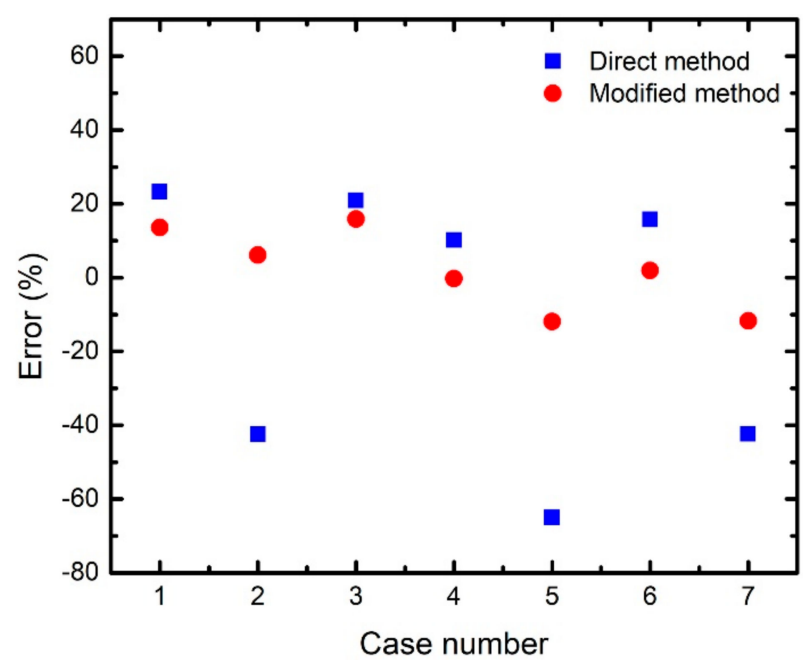

Figure 9. Estimated $\mathrm{O}_{2}$-concentration error as a function of case number for the direct (blue squares) and modified (red dots) methods. The experimental conditions of the various cases are presented in Table 1.

\section{Conclusions}

Fluorescence-based gas sensors have many advantages such as high detection sensitivity and cost effectiveness. It is even better if such sensors have the ability to sense multiple gases simultaneously because several species may coexist in many practical applications. A multi-gas sensor needs to identify not only the species but also the concentration of the detected gases. Such a sensor can be fabricated by using several distinct fluorescent dyes, each of which is sensitive to only one specific gas species. However, a real sensor may not have such specificity; the dye used for this sensor may be sensitive to more than one species. Such a phenomenon, called a cross-sensitivity effect, strongly hinders the development of fluorescence-based multi-gas sensors. In this work we systematically studied such an effect by using a trial fluorescence-based sensor which allowed us to sense oxygen and ammonia gases simultaneously. According to this study, we proposed a new analysis method to reduce the cross-sensitivity effect and thus improve the accuracy of gas concentration detection. This method has been tested by sensing seven arbitrarily selected atmospheres with different compositions of ammonia and oxygen gases. This analysis improves oxygen-detection error from $-11.4 \% \pm 34.3 \%$ to $2.0 \% \pm 10.2 \%$ in a mixed background of ammonia and nitrogen when compared with that neglecting the cross-sensitivity effect. Such an analysis method could probably be applied for other fluorescence-based multi-gas sensors to resolve their cross-sensitivity effects. Therefore, the proposed method is promising for the development of multi-gas sensors with higher accuracy in the detection of gas concentrations in real environments.

Author Contributions: Conceptualization, C.-Y.L., C.-S.C. and S.B.; methodology, C.-Y.L., C.-S.C. and S.B.; software, C.-S.C.; validation, C.-Y.L., C.-S.C., Y.-N.L., P.-T.H. and S.B.; formal analysis, C.-Y.L.; investigation, C.-Y.L., Y.-N.L. and S.B.; resources, C.-S.C. and S.B.; data curation, M.D., A.S.S., and R.K.; writing — original draft preparation, C.-Y.L.; writing—review and editing, C.-Y.L., Y.-N.L., P.-T.H., B.N.P., S.-H.C. and S.B.; visualization, B.N.P. and S.-H.C.; supervision, C.-Y.L.; project administration, S.B.; funding acquisition, S.B. All authors have read and agreed to the published version of the manuscript. 
Funding: This work was supported by the Ministry of Science and Technology, Taiwan (MOST 108-2639-M-001-003-ASP; MOST 105-2221-E-131-015-MY2; MOST 110-2221-E-131-019; MOST 1072221-E-131-029 -MY2; MOST 109-2221-E-131-005-MY2).

Institutional Review Board Statement: Not applicable.

Informed Consent Statement: Not applicable.

Data Availability Statement: Not applicable.

Conflicts of Interest: The authors declare no conflict of interest.

\section{Appendix A}

Fluorescence Peaks of PtTFPP Modified by Oxygen and Ammonia

Platinum(II) meso-tetrakis(pentafluorophenyl)porphyrin (PtTFPP) has two fluorescent peaks at $650 \mathrm{~nm}$ (called "peak 1" hereafter) and $710 \mathrm{~nm}$ (called "peak 2" hereafter). Both peaks can be quenched by environmental $\mathrm{O}_{2}$ and thus be used for oxygen sensing. In addition, they can be quenched by $\mathrm{NH}_{3}$ gas, too. In this section, we present our systematic study on the quenching effect caused by oxygen and by ammonia, respectively.

We fabricated a trial sensor containing PtTFPP for this study. Prior to the sensor fabrication, we synthesized a PtTFPP-containing solution by a process schematically shown by the flowchart in Figure A1a. PtTFPP dye $(0.05 \mathrm{~g})$ was dissolved in $10 \mathrm{~mL}$ of tetrahydrofuran (THF 99.9\%) to create a homogenously mixed solution. Ten $\mu \mathrm{L}$ of this solution was then mixed with $100 \mu \mathrm{L}$ of a liquid sol-gel matrix to form the PtTFPP-containing solution. The matrix was prepared as follows: We added $1.25 \mathrm{~g}$ of ethyl cellulose (EC) to a mixture containing $10 \mathrm{~mL}$ of toluene and $2.25 \mathrm{~mL}$ of $\mathrm{EtOH}(99.5 \%)$. After that, the mixed solution was capped and stirred magnetically until it was turned into a transparent sol-gel matrix.

The PtTFPP-containing solution was spin-coated $(150 \mathrm{rpm}$ for $20 \mathrm{sec}$ ) on one side of a piece of glass with a thickness of $0.7 \mathrm{~mm}$. The sample was then placed in air for $24 \mathrm{~h}$ to evaporate any residual solvent. Finally, the sample containing PtTFPP dye was fabricated. The sample functioned as a trial sensor which was able to adsorb oxygen and ammonia gases as schematically, as shown in Figure A1b. Such adsorbing affects the fluorescence emission of PtTFPP, which will be discussed below.

(a)

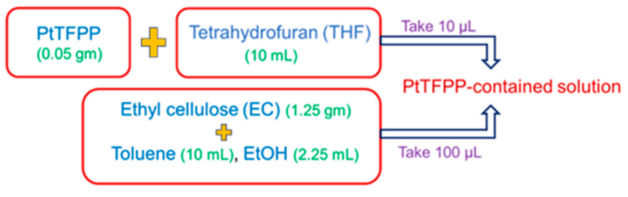

(b)

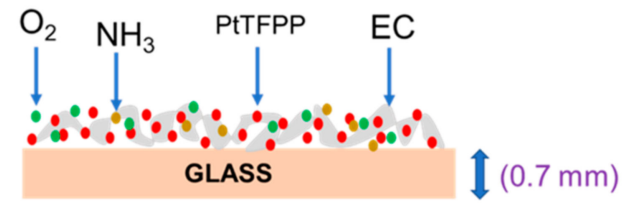

Figure A1. (a) A flow chart showing the synthesis processes of a PtTFPP-containing solution. (b) Schematic diagram representing a trial sensor adsorbing $\mathrm{O}_{2}$ and $\mathrm{NH}_{3}$ gases.

The trial sensor was placed into an optical sensing system, as schematically shown in Figure 3 in the main text, for detecting emission spectra in different oxygen or ammonia environments. Figure A2a shows the emission spectra from the sensor by systematically varying the $\mathrm{O}_{2}$ concentration in a $\mathrm{NH}_{3}$-free environment. Two fluorescence peaks (peaks 1 and 2) are observed in the spectra. Both the peaks are quenched gradually with increasing $\mathrm{O}_{2}$ concentration, indicating that they are sensitive to oxygen gas. In addition, the intensity of peak 1 (called " $\mathrm{I}_{1}$ " hereafter) is always larger than that of peak 2 (called " $\mathrm{I}_{2}$ " hereafter) for any oxygen concentration. Figure A2b shows the plot of $\mathrm{I}_{1}$ as a function of oxygen concentration. The reducing trend quantitatively displays the fluorescence quenching of 
peak 1 caused by environmental oxygen gas. The maximum detection sensitivity of peak 1 is calculated as 60 for $\mathrm{O}_{2}$ concentration of $100 \%$. Figure A2c shows the plot of $\mathrm{I}_{2}$ as a function of oxygen concentration. This figure also displays a reducing trend. The maximum sensitivity of peak 2 is calculated as 28 for an $\mathrm{O}_{2}$ concentration of $100 \%$. Figure A2d shows the plot of $\mathrm{I}_{1} / \mathrm{I}_{2}$ as a function of oxygen concentration. The $\mathrm{I}_{1} / \mathrm{I}_{2}$ gradually decreases from 5.6 to 2.7 while the corresponding oxygen concentration increases from $0 \%$ to $100 \%$. The reducing trend indicates that $I_{1}$ compared to $I_{2}$ is more sensitive to environmental oxygen concentration. Therefore, peak 1 is a better indicator for oxygen concentration sensing.
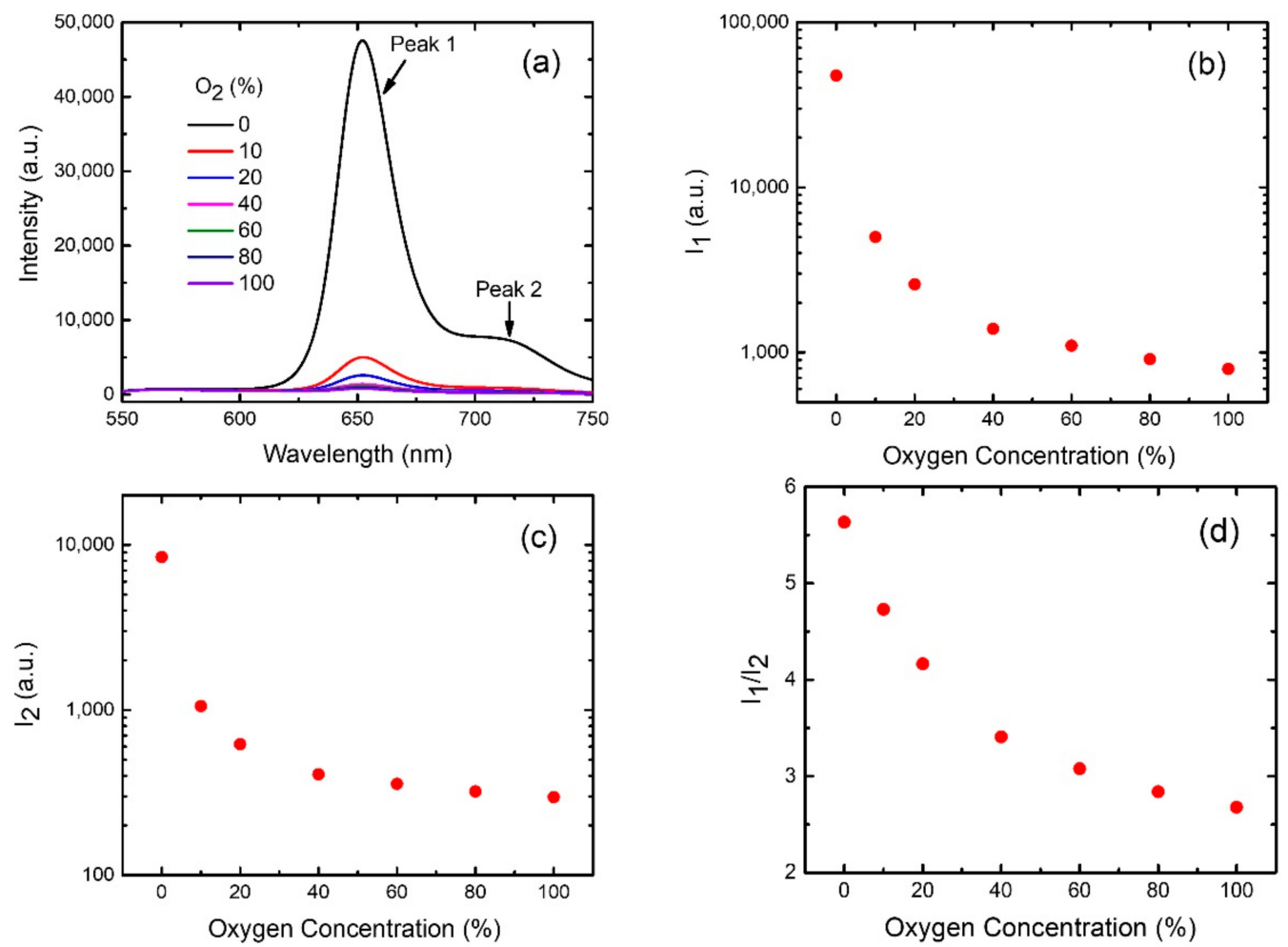

Figure A2. (a) Emission spectra of the trial sensor under systematically varying $\mathrm{O}_{2}$ concentration conditions in a $\mathrm{NH}_{3}$-free environment. The (b) $I_{1}$, (c) $I_{2}$, and (d) $I_{1} / I_{2}$ as a function of oxygen concentration are plotted based on the spectra in (a).

Figure A3a shows the emission spectra from another fresh trial sensor by systematically changing the $\mathrm{NH}_{3}$ concentration in a $\mathrm{O}_{2}$-free environment. Both peaks 1 and 2 are quenched gradually with increasing $\mathrm{NH}_{3}$ concentration, which indicates that they are sensitive to ammonia gas. In addition, $I_{1}$ is always larger than $I_{2}$ for any ammonia concentration. Figure A3b displays the plot of $\mathrm{I}_{1}$ as a function of the ammonia concentration. The reducing trend quantitatively shows the fluorescence quenching of peak 1 caused by environmental ammonia gas. The maximum sensitivity of peak 1 is calculated as 1.6 for a $\mathrm{NH}_{3}$ concentration of $1000 \mathrm{ppm}$. Figure $\mathrm{A} 3 \mathrm{c}$ shows the plot of $\mathrm{I}_{2}$ as a function of the ammonia concentration. A reducing trend is also observed in this figure. The maximum sensitivity of peak 2 is calculated as 1.5 for a $\mathrm{NH}_{3}$ concentration of $1000 \mathrm{ppm}$. The combined observation of Figures A2 and A3 leads to a conclusion that both peaks 1 and 2 suffer from cross-sensitivity effects in an environment simultaneously containing $\mathrm{O}_{2}$ and $\mathrm{NH}_{3}$. Figure A3d shows the plot of $\mathrm{I}_{1} / \mathrm{I}_{2}$ as a function of the ammonia concentration. The $\mathrm{I}_{1} / \mathrm{I}_{2}$ gradually decreases from 5.6 to 5.4 while the corresponding ammonia concentration increases from 0 to $1000 \mathrm{ppm}$. The variation of $\mathrm{I}_{1} / \mathrm{I}_{2}$ is quite small, which indicates that both the corresponding peaks have similar sensitivities for detecting ammonia. Our study provides useful information for using the fluorescence peaks of PtTFPP for oxygen concentration detection in an environment simultaneously containing $\mathrm{O}_{2}$ and $\mathrm{NH}_{3}$. 

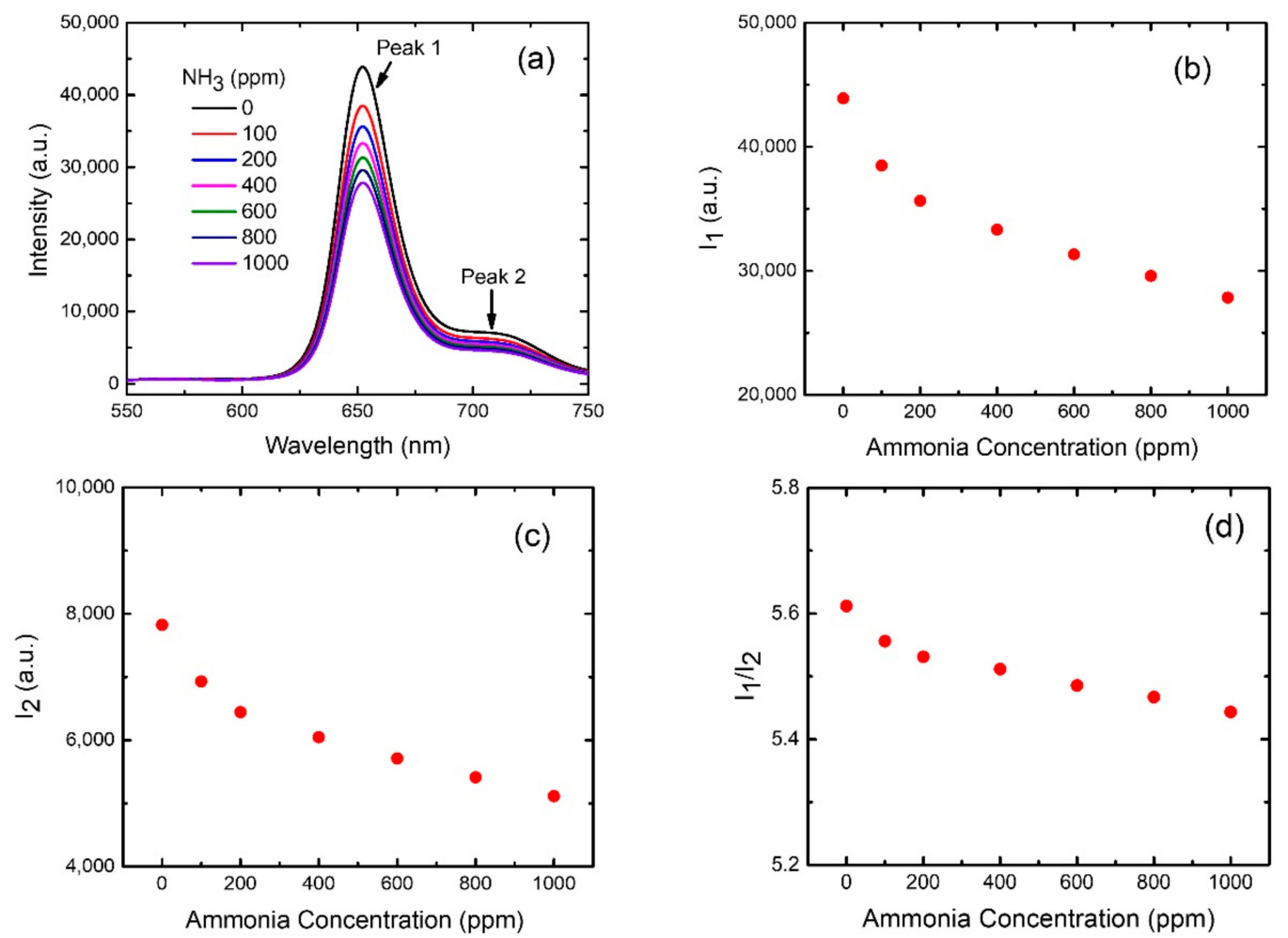

Figure A3. (a) Emission spectra of the trial sensor under systematically varying $\mathrm{NH}_{3}$ concentration in a $\mathrm{O}_{2}$-free environment. The (b) $\mathrm{I}_{1},(\mathbf{c}) \mathrm{I}_{2}$, and (d) $\mathrm{I}_{1} / \mathrm{I}_{2}$ as a function of ammonia concentration are plotted based on the spectra in (a).

\section{References}

1. Bogue, R. Detecting gases with light: A review of optical gas sensor technologies. Sens. Rev. 2015, 35, 133-140. [CrossRef]

2. Xiao, Z.H.; Kong, L.B.; Ruan, S.C.; Li, X.L.; Yu, S.J.; Li, X.Y.; Jiang, Y.; Yao, Z.J.; Ye, S.; Wang, C.H.; et al. Recent development in nanocarbon materials for gas sensor applications. Sens. Actuator B Chem. 2018, 274, 235-267. [CrossRef]

3. Zappa, D.; Galstyan, V.; Kaur, N.; Arachchige, H.; Sisman, O.; Comini, E. "Metal oxide -based heterostructures for gas sensors"—A review. Anal. Chim. Acta 2018, 1039, 1-23. [CrossRef]

4. Pelosi, P.; Zhu, J.; Knoll, W. From gas sensors to biomimetic artificial noses. Chemosensors 2018, 6, 32. [CrossRef]

5. Fang, X.; Zong, B.Y.; Mao, S. Metal-organic framework-based sensors for environmental contaminant sensing. Nano-Micro Lett. 2018, 10, 1-19. [CrossRef]

6. Nguyen, T.N.; Ebrahim, F.M.; Stylianou, K.C. Photoluminescent, upconversion luminescent and nonlinear optical metal-organic frameworks: From fundamental photophysics to potential applications. Coord. Chem. Rev. 2018, 377, 259-306. [CrossRef]

7. Borisov, S.M.; Seifner, R.; Klimant, I. A novel planar optical sensor for simultaneous monitoring of oxygen, carbon dioxide, $\mathrm{pH}$ and temperature. Anal. Bioanal. Chem. 2011, 400, 2463-2474. [CrossRef]

8. Bergman, I. Rapid-response atmospheric oxygen monitor based on fluorescence quenching. Nature 1968, 218, 396. [CrossRef]

9. Wolfbeis, O.S. Materials for fluorescence-based optical chemical sensors. J. Mater. Chem. 2005, 15, 2657-2669. [CrossRef]

10. Zou, X.S.; Pan, T.T.; Jiang, J.P.; Li, G.; Song, C.; Sun, R.F.; Yang, Z.Y.; Sun, D.Z.; Hou, C.H.; Chen, M.W.; et al. Poly( $\varepsilon$-caprolactone)containing graft copolymers for ratiometric extracellular oxygen sensing. Sens. Actuator B Chem. 2017, 248, 108-118. [CrossRef]

11. Chu, C.S.; Syu, J.J. Optical sensor for dual sensing of oxygen and carbon dioxide based on sensing films coated on filter paper. Appl. Opt. 2017, 56, 1225-1231. [CrossRef]

12. Wolfbeis, O.S.; Weis, L.J.; Leiner, M.J.P.; Ziegler, W.E. Fiber-optic fluorosensor for oxygen and carbon-dioxide. Anal. Chem. 1988, 60, 2028-2030. [CrossRef]

13. Borisov, S.M.; Krause, C.; Arain, S.; Wolfbeis, O.S. Composite material for simultaneous and contactless luminescent sensing and imaging of oxygen and carbon dioxide. Adv. Mater. 2006, 18, 1511-1516. [CrossRef]

14. Amao, Y.; Asai, K.; Okura, I.; Shinohara, H.; Nishide, H. Platinum porphyrin embedded in poly(1-trimethylsilyl-1-propyne) film as an optical sensor for trace analysis of oxygen. Analyst 2000, 125, 1911-1914. [CrossRef]

15. Amao, Y. Probes and polymers for optical sensing of oxygen. Microchim. Acta 2003, 143, 1-12. [CrossRef]

16. Fu, Y.Y.; Xu, W.; He, Q.G.; Cheng, J.G. Recent progress in thin film fluorescent probe for organic amine vapour. Sci. China Chem. 2016, 59, 3-15. [CrossRef] 
17. Chu, C.S.; Lo, Y.L.; Sung, T.W. Review on recent developments of fluorescent oxygen and carbon dioxide optical fiber sensors. Photonic Sen. 2011, 1, 234-250. [CrossRef]

18. Donald, K.W. Oxygen poisoning in man. Br. Med. J. 1947, 1, 712-717. [CrossRef] [PubMed]

19. Timmer, B.; Olthuis, W.; Van Den Berg, A. Ammonia sensors and their applications-A review. Sens. Actuator B Chem. 2005, 107, 666-677. [CrossRef]

20. Yeh, T.S.; Chu, C.S.; Lo, Y.L. Highly sensitive optical fiber oxygen sensor using Pt(II) complex embedded in sol-gel matrices. Sens. Actuator B Chem. 2006, 119, 701-707. [CrossRef]

21. Chu, C.S.; Lo, Y.L. High-performance fiber-optic oxygen sensors based on fluorinated xerogels doped with Pt(II) complexes. Sens. Actuator B Chem. 2007, 124, 376-382. [CrossRef]

22. Markovics, A.; Nagy, G.; Kovacs, B. Reflection-based sensor for gaseous ammonia. Sens. Actuator B Chem. 2009, $139,252-257$. [CrossRef]

23. Chu, C.S.; Lo, Y.L.; Sung, T.W. Enhanced oxygen sensing properties of Pt(II) complex and dye entrapped core-shell silica nanoparticles embedded in sol-gel matrix. Talanta 2010, 82, 1044-1051. [CrossRef]

24. Chu, C.S.; Lo, Y.L. Highly sensitive and linear calibration optical fiber oxygen sensor based on Pt(II) complex embedded in sol-gel matrix. Sens. Actuator B Chem. 2011, 155, 53-57. [CrossRef]

25. Wang, X.J.; Li, C.L.; Huang, Y.W.; Zhai, H.Y.; Liu, Z.H.; Jin, D.Z. Highly sensitive and stable perylene sensor for ammonia detection: A case study of structure-property relationships. Sens. Actuator B Chem. 2018, 275, 451-458. [CrossRef]

26. Raghu, A.V.; Karuppanan, K.K.; Pullithadathil, B. Highly sensitive, temperature-independent oxygen gas sensor based on anatase $\mathrm{TiO}_{2}$ nanoparticle grafted 2D mixed balent $\mathrm{VO}_{\mathrm{x}}$ nanoflakelets. ACS Sens. 2018, 3, 1811-1821. [CrossRef] [PubMed]

27. Muckley, E.S.; Collins, L.; Ievlev, A.V.; Ye, X.Y.; Kisslinger, K.; Sumpter, B.G.; Lavrik, N.V.; Nam, C.Y.; Ivanov, I.N. Light-activated hybrid nanocomposite film for water and oxygen sensing. ACS Appl. Mater. Interfaces 2018, 10, 31745-31754. [CrossRef]

28. Tanguy, N.R.; Thompson, M.; Yan, N. A review on advances in application of polyaniline for ammonia detection. Sens. Actuator $B$ Chem. 2018, 257, 1044-1064. [CrossRef]

29. Biring, S.; Sadhu, A.S.; Deb, M. An effective optical dual gas sensor for simultaneous detection of oxygen and ammonia. Sensors 2019, 19, 5124. [CrossRef]

30. Elosua, C.; De Acha, N.; Hernaez, M.; Matias, I.R.; Arregui, F.J. Layer-by-Layer assembly of a water-insoluble platinum complex for optical fiber oxygen sensors. Sens. Actuator B Chem. 2015, 207, 683-689. [CrossRef]

31. Peng, L.R.; Yang, X.H.; Yuan, L.B.; Wang, L.L.; Zhao, E.M.; Tian, F.J.; Liu, Y.X. Gaseous ammonia fluorescence probe based on cellulose acetate modified microstructured optical fiber. Opt. Commun. 2011, 284, 4810-4814. [CrossRef]

32. Wang, H.H.; Liu, C.Y.; Wu, S.B.; Liu, N.W.; Peng, C.Y.; Chan, T.H.; Hsu, C.F.; Wang, J.K.; Wang, Y.L. Highly Raman-enhancing substrates based on silver nanoparticle arrays with tunable sub-10 nm gaps. Adv. Mater. 2006, 18, 491-495. [CrossRef]

33. Liu, C.Y.; Biring, S. Nanoplatform based on ideally ordered arrays of short straight and long beer bottle-shaped nanochannels. Microporous Mesoporous Mater. 2019, 287, 71-76. [CrossRef]

34. Liu, C.Y.; Wang, Y.L. Creating anodic alumina nanochannel arrays with custom-made geometry. J. Chin. Chem. Soc. 2020, 67, 11-24. [CrossRef]

35. Liu, C.S.; Li, J.J.; Pang, H. Metal-organic framework-based materials as an emerging platform for advanced electrochemical sensing. Coord. Chem. Rev. 2020, 410, 213222. [CrossRef]

36. Dong, C.J.; Zhao, R.J.; Yao, L.J.; Ran, Y.; Zhang, X.; Wang, Y.D. A review on $\mathrm{WO}_{3}$ based gas sensors: Morphology control and enhanced sensing properties. J. Alloys Compd. 2020, 820, 153194. [CrossRef]

37. Lee, J.S.M.; Cooper, A.I. Advances in conjugated microporous polymers. Chem. Rev. 2020, 120, 2171-2214. [CrossRef]

38. Lakowicz, J.R. Principles of Fluorescence Spectroscopy, 3rd ed.; Springer: New York, NY, USA, 2006; pp. $278-327$.

39. Carraway, E.R.; Demas, J.N.; Degraff, B.A. Luminescence quenching mechanism for microheterogeneous systems. Anal. Chem. 1991, 63, 332-336. [CrossRef]

40. Demas, J.N.; Degraff, B.A.; Xu, W.Y. Modeling of luminescence quenching-based sensors: Comparison of multisite and nonlinear gas solubility models. Anal. Chem. 1995, 67, 1377-1380. [CrossRef] 